the precipitate in a warm room and its consequent partial drying. There is no evidence here nor in the previous cases of the formation of any definite thiosulphate and we would question its existence under ordinary conditions. There is no evidence of the formation here of an hydroxide as one of the authors quoted states. Basic salts seem to be the only products.

UNIVERSITY OF NORTH CAROLINA, March, 1895 .

\title{
ON SOME CONDITIONS AFFECTING THE ACCURACY OF THE DETERMINATION OF POTASH AS POTAS- SIUM PLATINICHLORIDE.
}

By A. L. Winton, Connecticut Agricultural Experiment Station. Received April 2, 1895 .

I the course of some determinations of potash in potassium chloride, made by direct evaporation with platinum solution preliminary to a further study of methods, it was observed that the potassium platinichloride was more finely divided and the results were higher when the solution of the potash salt was concentrated on adding the reagent, than when it was dilute.

In order to ascertain the real connections of the facts observed, I then made a series of experiments which were all conducted in exactly the same way, except for the kind of dish used, the dilution of the solution of potassium chloride on adding the platinum solution, the presence or not of added hydrochloric acid, the temperature of the water-bath, and the strength of alcohol used for washing.

The potassium chloride used was from a lot sent by Dr. H. J. Wheeler, Reporter on Potash, for the Association of Official Agricultural Chemists. After being finely ground, it contained 0.45 per cent. of moisture, which was determined by heating below a red heat over a lamp until constant weight was secured. In each case, approximately one-half gram was weighed out from a weighing bottle. After solution in water and adding platinum solution, the mixture was evaporated to a pasty condition, and about twenty-five $c c$. of alcohol were added and allowed to stand on the potassium platinichloride for one hour with repeated stirring. The precipitates were then collected in 
Gooch crucibles, washed with about $100 \mathrm{cc}$. of alcohol, and dried to constant weight, first at $100^{\circ} \mathrm{C}$. and finally at $130^{\circ} \mathrm{C}$. The results calculated to potassium chloride by the use of the factor 0.3056 and expressed in per cents. of the quantity taken, are given in Table I.

It will be seen from the table that neither the kind of dish used, nor the temperature of the solution of potassium chloride on adding the platinum solution, nor the presence of a large excess of hydrochloric acid, during evaporation, nor the temperature of evaporation, had any perceptible influence on the results.

These points, therefore, need not be further considered. In most of the experiments ninety-five per cent. alcohol was used in order to dininish the solubility of the potassium platinichloride. In experiments Nos. 9, 10, 29, and 30 , however, the alcohol was eighty per cent., and the results are, for this reason, somewhat lower.

The Iffect of Dilution of the Solution when Potassium Chloride with no Admixture is used. - The principal point brought out by the experiments is the effect of the dilution of the potassium chloride solution when chloroplatinic acid is added, on the character of the potassium platinichloride, and the results.

If the potassium chloride were dissolved in fifty cc. of water, the potassium platinichloride was either not precipitated at all on addition of the platinum solution, or else went into solution when the liquid became heated, and was then deposited slowly on evaporation.

The potassium platinichloride thus obtained was invariably in brilliant, orange-colored granular crystals, which were often united to form plates from one to five mm. across. Constant weight was secured after drying the double sait for three hours at ${ } \mathrm{C}^{\circ} \mathrm{C}$., the results of several deterninations being concordant and slightly below theory. The loss on furtier drying at $130^{\circ}$ was very small.

But if, on the other hand, ten cc. or less of water were used to dissolve the potassium chloride, a considerable portion of the potassium platinichloride precipitated as a fine powder immediately on adding the reagent, the remainder being deposited on evaporation. After treating with alcohol and filtering, 


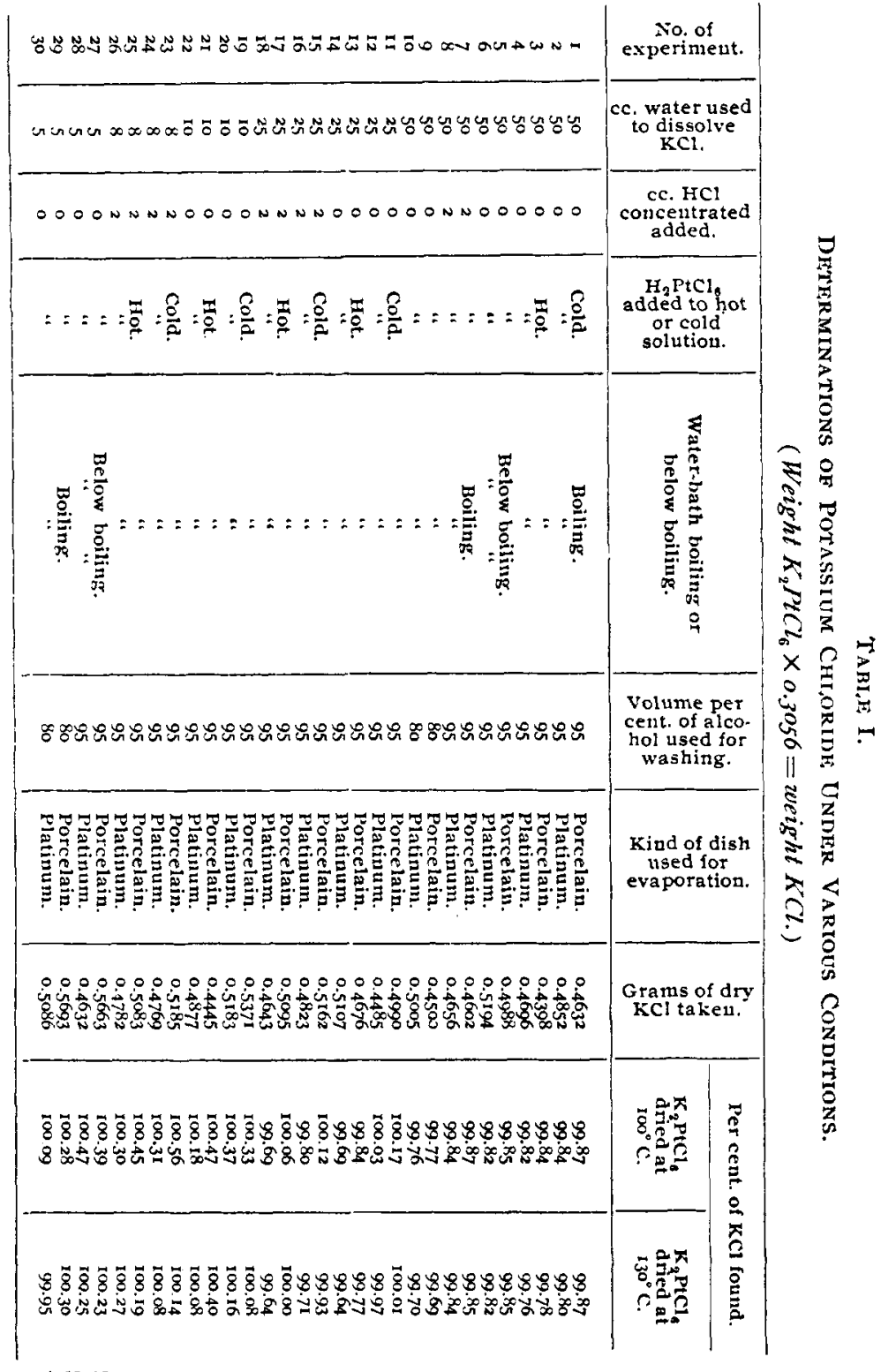

$4-30-95$ 
the salt presented the appearance of a fine, yellow powder, with generally an occasional granular crystal. Constant weight at $100^{\circ}$ was only secured after heating from nine to fifteen hours, the results, although not always concordant, being in every case considerably above theory. Heating for many hours at $I 30^{\circ} \mathrm{C}$. further reduced the results, although even after this treatment they were still slightly above theory.

The difference in the results obtained in dilute and concentrated solutions, is brought out strikingly by the averages given in the following table:

TABLE: II.

AVERAGES OF RrSUltS OHTAINED IN DILUTE ANT CONCENTRATED SORTTIONS OF PO'TASSITM CHLORIDE.

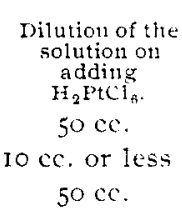

5

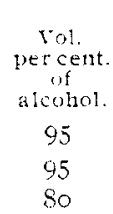

So

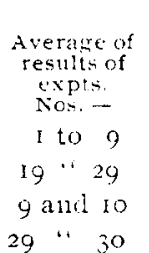

29 " 30

\begin{tabular}{|c|c|}
\hline $\begin{array}{l}\mathrm{K}_{2} \mathrm{P}^{2} \mathrm{Cl} \mathrm{I}_{\alpha} \\
\mathrm{dried} \text { at } \\
100^{\circ} \mathrm{C}\end{array}$ & $\begin{array}{l}\mathrm{K}_{2} \mathrm{PtCl}_{\mathrm{\beta}} \\
\text { dried at } \\
\mathrm{I}_{3}, 0^{\circ} \mathrm{C}\end{array}$ \\
\hline 99.84 & 99.82 \\
\hline 100.38 & 100.17 \\
\hline $99 \cdot 77$ & 99.69 \\
\hline 100.20 & 99.98 \\
\hline
\end{tabular}

The average of eight closely agreeing results, using fifty cc. of water and ninety-five per cent. alcohol and drying at $100^{\circ} \mathrm{C}$. is 99.84 per cent. potassium chloride. After drying at $130^{\circ} \mathrm{C}$. the average is only 0.02 per cent. lower. But where the conditions were the same, except that only ten cc. or less of water were used to dissolve the potassium chloride, the average of ten results is 100.38 per cent. potassium chloride, after drying at $100^{\circ} \mathrm{C}$., and 100.17 per cent. or 0.2 I per cent. lower, after drying at $130^{\circ} \mathrm{C}$. The results after drying at $100^{\circ} \mathrm{C}$. and $130^{\circ} \mathrm{C}$. are. on an average, 0.16 and 0.18 per cent. respectively below theory, whereas in concentrated solutions they are 0.38 and 0.17 per cent. respectively, above theory:

The results, using eighty per cent. alcohol, although all rather lower, show similar differences.

In the cases where the potassitnm chloride was dissolved in tweuty-five $c c$. of water the restlts generally agree with those where fifty $c c$. of liquid was present, although not always.

In Table III are given the per cents. of potassium chloride corresponding to the average losises in weight of the potassium 
platinichloride during successive periods at $100^{\circ}$ and $130^{\circ} \mathrm{C}$., in the case of ten determinations using fifty $\mathrm{cc}$. of water and of twelve using ten cc. or less of water.

TABLE III.

Showing the Average Rate of Drying of Potassium PlatiniCHLORIDE OBTAINED FROM DILUTE AND CONCENTRATED Solutrons.

(The first heating of three hours at $100^{\circ} \mathrm{C}$. is not considered.)

\begin{tabular}{|c|c|c|c|c|}
\hline & & & $\begin{array}{l}r \text { cent. of } \mathrm{K} \\
\text { loss in we }\end{array}$ & $\begin{array}{l}\text { rresponding to } \\
\text { of } \mathrm{K}_{2} \mathrm{PtCl}_{8} \text {. }\end{array}$ \\
\hline$\underset{\text { heated }}{\mathrm{K}_{2} \mathrm{Ptc}}$ & & $\begin{array}{l}\text { Di1 } \\
\text { Ave }\end{array}$ & $\begin{array}{l}\text { ute solutions. } \\
\text { rage of expts. } \\
\text { os. I to II. }\end{array}$ & $\begin{array}{l}\text { Concentrated } \\
\text { solutions. } \\
\text { Average of expts. } \\
\text { Nos. yg to } 3 . \mathrm{I} .\end{array}$ \\
\hline $100^{\circ} \mathrm{C} .3$ & Lut & $s \ldots . . . . .$. & 0.019 & 0.062 \\
\hline 3 & “ & $\ldots \ldots \ldots \ldots$ & 0.003 & 0.036 \\
\hline 3 & “ & $\ldots \ldots \ldots$. & 0.003 & 0.022 \\
\hline 3 & “ & $\ldots \ldots \ldots$ & 0.000 & 0.003 \\
\hline Tot & $1 \ldots$ & . $\ldots \ldots \ldots$ & 0.025 & 0.123 \\
\hline $130^{\circ} \mathrm{C} .71$ & lout & $5 \ldots . . . . . .$. & 0.025 & 0.088 \\
\hline 7 & $" ،$ & ........... & 0.006 & 0.058 \\
\hline 7 & “ & $\ldots \ldots \ldots \ldots$ & 0.000 & 0.035 \\
\hline 7 & " & $\ldots \ldots \ldots \ldots$ & 0.000 & 0.020 \\
\hline 7 & “" & $\ldots \ldots \ldots \ldots$ & 0.000 & 0.010 \\
\hline 7 & " & $\ldots \ldots \ldots$ & 0.000 & 0.003 \\
\hline Tot & 11. & . $\cdots \cdots$ & 0.031 & 0.214 \\
\hline $10^{\circ}$ and & $30^{\circ}$ & total....... & $0.05^{6}$ & 0.337 \\
\hline
\end{tabular}

The Effect of the Dilution of the Solution when Potassium Chloride with other Salts and Sulphuric Acid is used.-Following a method, such as the so-called alternate method of the Association of Official Agricultural Chemists, the solution to which platinum solution is added, should contain only sodium and potassium chlorides, having been previously freed from other matters.

In experiments Nos. 33 and 34 , in Table IV, the solution contains about one part of potassium chloride to one and onehalf parts sodium chloride, which is the ratio of these salts in kainite, the richest in soda of the commercial potash manure salts. In experiments Nos. 35 and 36 , the ratio of the two salts, is approximately as one to one-half. 
In analyses by the Lindo-Gladding method, however, part or all of the potash nay exist as sulphate in the solution to which platinum solution is added and sodium and magnesium sulphates and chlorides may also be present.

In experiments Nos. 37 and 38 about the same proportions of magnesium sulphate as would be present in kainite were added, and in experiments Nos. 39 and 40 two parts of sulphuric acid were added to one part of potassium chloride.

In all these experiments platinum dishes were used, no hydrochloric acid was added, the platinum solution was added to the hot solution of the salts, the evaporation was carried on over boiling water-baths, and eighty per cent. alcohol was used for washing. The quantities of potassium chloride taken varied from 0.24 to 0.50 gram. In the case of experiments Nos. 37 and 38 , where magnesium sulphate was present, the potassium platinichloride, after being collected on Gooch crucibles, was washed with $5_{50} \mathrm{cc}$. of Gladding's reagent, ${ }^{1}$ and then with eighty per cent. alcohol.

The double salt was, in each case, not only dried at $100^{\circ}$ and $130^{\circ}$, but also at $160^{\circ} \mathrm{C}$. In other respects the work was conducted as clescribed for previous experiments. Results are given in Table IV.

In these experiments the dilution of the solution had the same effect on the form of the potassium platinichloride, the rate of drying, and the results obtained as in those previously made on potassium chloride alone.

The granular crystals obtained from dilute solutions after drying for two hours at $100^{\circ}$ did not lose more than 0.06 per cent. during subsequent heating of many hours at $100^{\circ}, 130^{\circ}$, and $160^{\circ}$ C., the pulverulent form precipitated in concentrated solutions, however, continued to lose in weight during successive periods of heating, the total loss being in no case less than 0.50 per cent. Determined in the presence of the same weight of the same kind of impurity the per cents. of potassium chloride calculated from the weight of potassium platinichloride dried at $100^{\circ} \mathrm{C}$. are considerably higher when the solution was concentrated than

1 A solution of one part of ammonium chloride in five parts of water which has been saturated in the cold with potassium platinichloride. 
POTASH AS POTASSIUM PLATINICHLORIDE.

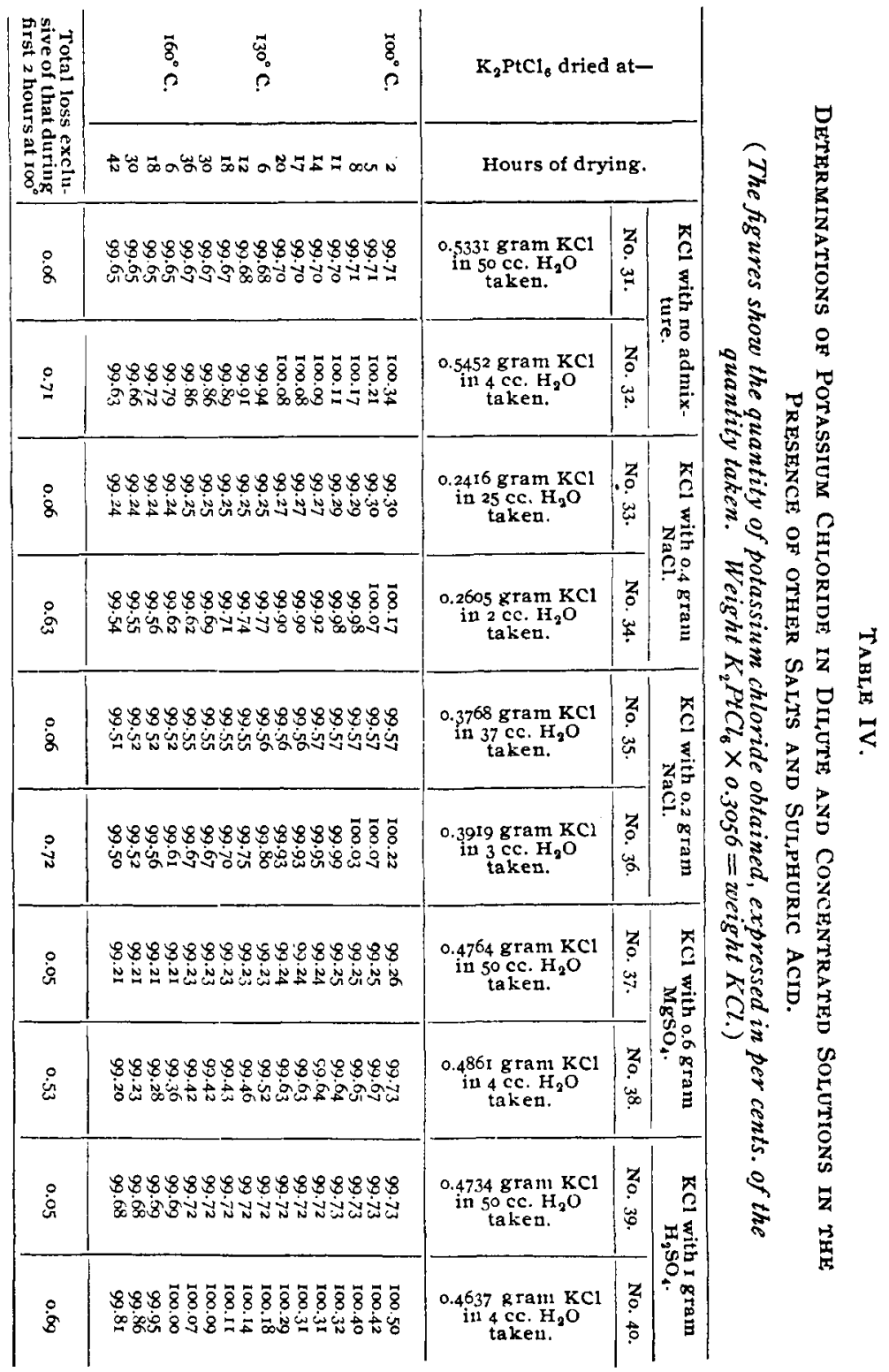


when it was dilute, but calculated from the weights after drying at $160^{\circ} \mathrm{C}$. they are about the same.

Experiments Nos. 39 and to are practically equivalent to determinations on potassium sulphate with the addition of hydrochloric and sulphuric acids, the amount of the latter acid being about double that necessary to combine with the potassium to form the sulphate. Since in these experiments the results were practically the same as when no sulphuric acid was added, it is reasonable to assume that the effect of the dilution of the solution is the same whether the potash exists as chloride or sulphate.

In both dilute and concentrated soluticns the results obtained in the presence of sodium chloride or magnesium sulphate, were lower than when determinations were made on potassium chloride with no admixture, or with only sulphuric acid.

In the presence of sodium chloride this was due partly, if not entirely, to the smaller quantity of potassium chloride taken. Since about the same amount of alcohol was used in all cases, the percentage error due to solubility of potassium platinichloride in alcohol would be greater, the smaller the quantity of the salt taken, although the actual weight lost might be the same.

In the two experiments where magnesium sulphate was present, the washing with Gladding's reagent and the second washing with a!cohol undoubtedly increased the minus errors. Possibly the mere presence of sodium and magnesium salts depresses the results. The fact that the results are lower does not impair their value for the present purpose, as in each case the experiments with the sanne admixture were both made on nearly the same weight of potassium chloride and in exactly the same manner, except as regards the dilution of the solution.

Results of Fresenius.-R. Fresenius ${ }^{1}$ in an article published in 1877 describing his method for determining potash as potassium platinichloride, directs to add platinum solution to a concentrated solution of the potash salt, wash with eighty per cent. (by volume) alcohol, and dry the potassium platinichloride to constant weight at $130^{\circ} \mathrm{C}$.

In a later article ${ }^{2}$ he gives the following results obtained by this

1 Zlsch, anal. chem, 16,6,3.

2 Zischr. anal. Chem., $2 \mathrm{r}, 2.38$ 
method on pure potassium chloride, with and without the addition of sodium chloride, using the factor 0.3056 . He states that the potassium platinichloride was obtained in the form of a fine pozeder.

\section{TABLE V.}

ResUlts of R. Fresenius on POTASSIUM ChLoride with and Without ADdition of Sodium CHLORIDE.

(The figures show the quantity of Potassium Chloride obtained, expressed in per cents. of the quantity taken. Wt. $\mathrm{K}_{2} \mathrm{PtCl}_{6} \times 0.3056=$ weight. $\mathrm{KCl}$.)

\begin{tabular}{|c|c|c|c|c|c|}
\hline $\begin{array}{l}\text { Hours } \\
\text { dried at } \\
130^{\circ} \text {. }\end{array}$ & $\begin{array}{l}1.037^{8} \mathrm{gram} \\
\text { KCl taken. }\end{array}$ & $\begin{array}{l}0.9563 \text { gram } \\
\text { KC1 taken. }\end{array}$ & $\begin{array}{l}\text { Hours } \\
\text { dried at } \\
\mathrm{I} 3^{\circ} 0^{\circ} \text {. }\end{array}$ & $\begin{array}{l}0.9490 \text { gram } \\
\text { KCl and } \\
0.1189 \text { gram } \\
\text { NaCl taken. }\end{array}$ & $\begin{array}{l}0.6812 \text { gram } \\
\text { KC1 and } \\
0.4524 \text { gram } \\
\text { Nacl taken }\end{array}$ \\
\hline 2 & 100.67 & 100.42 & 5 & 100.19 & 100.13 \\
\hline 7 & $100.4^{\circ}$ & 100.16 & 8 & I00. I I & 100.06 \\
\hline I 2 & 100.23 & 100.04 & II & 100.04 & 99.98 \\
\hline $2 \mathrm{I}$ & 10.19 & $100 . \infty$ & 14 & 100.02 & 99.97 \\
\hline 30 & 100.10 & 99.93 & 20 & 100.00 & 99.94 \\
\hline
\end{tabular}

The results of Fresenius without addition of sodium chloride are corroborated by my results in experiments Nos. 29 and 30 in Table I, and No. 32 in Table IV. In experiments Nos. I9 to 29, Table I, the results are a little higher, due to the lesser solubility of potassium platinichloride in ninety-five per cent. alcohol. The results given in Table IV, where sodium chloride was present, are somewhat lower than those of Fresenius, owing probably to the smaller weights of potassium chloride taken. If the factor, based on the latter and now generally accipted atomic weight of platinum as determined by Seubert, had been used, the results would be 0.42 per cent. higher.

There must be then some considerable plus error which more than compensates for the errors due to the solubility of the salt in alcohol and the use of the wrong atomic weight of platinum. This error is largely attributable to the presence of water in the potassium platinichloride.

Seubert' finds that it is difficult to so prepare this salt that it will be free from "verknisterungs wasser," which is not completely removed even at $160^{\circ} \mathrm{C}$. The slow drying of the pulverulent potassium platinichloride at $100^{\circ} \mathrm{C}$., and the further loss in weight after subsequent drying at $130^{\circ} \mathrm{C}$. is in harmony with Seubert's experience. The results after drying for many hours

1 Ann. Chem, 207, I. 
at $\mathrm{r} 30^{\circ} \mathrm{C}$. are very close to theory, where eighty per cent. alcohol was used, notwithstanding the solubility of the salt, and are higher if the alcohol were ninety-five per cent.

Microscopic Examination of the Potassium Platinichloride.-It has been already stated that the potassium platinic salt, when deposited on evaporation of dilute solutions, was coarsely crys: talline, while obtained from concentrated solutions, it was finely pulverulent. Examined under the microscope, the difference was even more striking. The coarse form was found to consist of octahedrons, generally attached to one another, forming thin plates, and corresponded to the descriptions usually given in the books, but when the salt was pulverulent, it consisted largely of curious radiating crystals, a characteristic form consisting of three bars intersecting at right angles to each other. Resting on three of the six arms, they presented at first sight, the appearance of stars with six arms in the same place, but by careful focussing, their true form was revealed.

Prof. S. L. Penfield, of Vale University, has very kindly examined my precipitates, and reports as follows:

Both forms of crystals belong to the isometric system. The coarse crystals being deposited slowly, are normal octahedrons; the pulverulent crystals, however, owing to their rapid formation, are very much distorted being developed into rods, crossing at $90^{\circ}$, parallel to the direction of the isometric axes.

In both the octahedrons and the interpenetrating rods, there were globular carities which, before drying, were undoubtedly filled with mother-liquor. Only an occasional cavity could be seen in the octahedrons, but in the rods they were very abundant.

Even after the long continued heating at $130^{\circ} \mathrm{C}$. ocular proof was secured that the octahedrons were not entirely dry. Patient search revealed the presençe of minute cavities from 0.003 to 0.01 mm. across, which were still partially filled with liquid. On inclining the stage about $45^{\circ}$ and revolving it about its center, a bubble could be scen to move from one side to the other exactly as the bubble moves in a spirit level.

The facts disclosed by Prof. Penfeld's examination, explain the slow drying in my experiments. The octahedrons, being comparatively free from inclosed liquid, did not lose greatly in 
weight on heating; the interpenetrating rods, however, contained a very considerable amount of inclosed liquid, part of which was slowly given off on heating at $100^{\circ}$, more at $130^{\circ}$, and still more at $160^{\circ} \mathrm{C}$.

The quantity of liquid enclosed in the octahedrons could not have been considerable, but it shows the persistence with which water, once enclosed, is retained.

Conclusions. - The method of precipitating in concentrated solutions, and drying the potassium platinichloride at $130^{\circ}$ depends, for its accuracy, on the compensation of three errors, due ( $I$ ) to the solubility of the potassium platinic salt in eighty per cent. alcohol, (2) to the presence of water in the crystals which is not driven off at $130^{\circ}$, and $(3)$ to the use of a factor based on the wrong atomic weight of platinum. Such a method is certainly open to criticism. The solubility in alcohol occasions an error that can hardly be avoided. It could be diminished by using ninety-five per cent. alcohol, but further experiments would be necessary in order to ascertain whether for other reasons the stronger alcohol could be advantageously substituted for the weaker.

The results given herewith show that the error occasioned by the presence of water can be greatly reduced and the process of drying simplified, by adding the platinum solution to a dilute solution of the potash salt (one part of potassium chloride or six-tenths part potassium oxide to roo cc. of water) and drying the potassium platinichloride at $100^{\circ} \mathrm{C}$. It is not clained that the double salt thus obtained is perfectly dry, but it is necessary to heat the pulverulent form for many hours at $160^{\circ} \mathrm{C}$. in order to secure it as free from water as the granular crystals obtained by the above sinple process.

The liquid enclosed in the crystals, although largely water, must contain also solid matters, which remain behind, however complete may be the drying. It must then follow that the less liquid inclosed at the outset, the smaller the error due to this cause after drying.

With such a simple method at our disposal for obtaining the potassium platinic salt comparatively free from moisture, the necessity for using an erroneous factor at once disappears.

The factors based on the atomic weights as revised by $F$. W. 
Clarke', up to January 1,1894 , would be 0.30688 for potassium chloride, and 0.1939 for potassium oxide. These factors would make all the foregoing results 0.42 per cent. higher in potassiun chloride, which is equivalent to 0.26 per cent. higher in potassium oxide.

In Table VI are given comparative results by the old and new factors, in the cases of all the preceding experiments in which one part of potassium chloride was dissolved in approximately IoO parts of water, and the potassium platinichloride was washed with eighty per cent. alcohol and dried two or three hours at I $00^{\circ} \mathrm{C}$.

TABLE VI.

COMPARISON OF RESUI,TS OBTAINED BY THE FACTORS 0.3056 AND 0.30688 FOR CALCULATING POTASSIUM ChLORIDE FROM POTASSIUM

PLATINICHIORIDE.

(Chloroplatinic Acid added to Dilute Solutions of Potassium Chloride, Potassium Platinichloride washed with cighty per ent. Alcohol and dried two to three hours at $100^{\circ} \mathrm{C}$.)

\begin{tabular}{|c|c|c|c|}
\hline \multirow{2}{*}{$\begin{array}{l}\text { Expt. } \\
\text { No. }\end{array}$} & \multirow[b]{2}{*}{ Material taken. } & \multicolumn{2}{|c|}{$\begin{array}{l}\text { Per cent. } \mathrm{KCl} \text { found } \\
\text { using factor. }\end{array}$} \\
\hline & & 0.3056 & 0.30688 \\
\hline 9 & 0.4500 gram $\mathrm{kCl} \ldots \ldots \ldots \ldots \ldots$ & 99.77 & 100,19 \\
\hline 10 & 0.5005 gram $\mathrm{KCl} \ldots \ldots \ldots \ldots \ldots \ldots \ldots \ldots \ldots$ & $99.7^{6}$ & 100.18 \\
\hline $3 I$ & 0.5331 gran $\mathrm{KCl}, \ldots \ldots \ldots \ldots \ldots \ldots \ldots \ldots$ & 99.71 & 100.13 \\
\hline 33 & 0.2416 gram $\mathrm{KCl}$ and 0.4 gram $\mathrm{NaCl} \ldots \ldots \ldots$ & $90 \cdot 30$ & $99 \cdot 72$ \\
\hline 35 & 0.3768 gram $\mathrm{KCl}$ and 0.2 gram $\mathrm{NaCl} \ldots \ldots$ & 99.57 & 99.99 \\
\hline 37 & 0.4764 gram $\mathrm{KCl}$ and 0.6 gram $\mathrm{MgSO}_{4} \ldots \ldots$ & 99.26 & 99.68 \\
\hline 39 & 0.4734 gram $\mathrm{KCl}$ and 1.0 gram $\mathrm{H}_{2} \mathrm{SO}_{1} \ldots \ldots$ & 99.73 & $10 \% 15$ \\
\hline
\end{tabular}

It will be seen that when potassium chloride, either alone, or mixed with sulphuric acid was taken, the results using the factor 0.30688 are 0.13 to 0.19 per cent. above theory. This would indicate either that the water remaining in the double salt after drying for two or three hours at $100^{\circ} \mathrm{C}$. a little more than compensated for the solubility in alcohol, or else that there are other slight plus errors.

When, however, other salts are present, and particularly if

1 L. S. Dept. Agr., Chem. Div., Bull. 43, p. 340.

Potassium $=39.4 \mathrm{r}$.

Platiuum $=195.00$.

Oxygen $=16.0$

chlorine $=35.45$. 
the Gladding method were followed, the tendency is toward lower results.

Taken as a whole the new factor gave, in these instances, more satisfactory results than the old factor.

A method which so reduces the error due to inclosed water in the double salt, that it about compensates for the solubility in alcohol, and which employs the factor based on the revised atomic weights, is, in my opinion, to be preferred to one which depends, for the accuracy of results, on the compensation of three errors, one of which is due to the use of a factor known to be incorrect, especially when the former method gives more con* cordant results and is more readily carried out.

Summary. - When chloroplatinic acid was added to a concentrated solution of potassium chloride, a large part of the potassium platinichloride formed was precipitated at once in a pulverulent form, the remainder being deposited on evaporation. After treating with alcohol, filtering, and drying, the double salt was in a fine powder which, examined under the microscope, was found to consist largely of radiating crystals, a characteristic form having six arms, formed by the intersection at right angles of three bars. Numerous globular cavities in the crystals gave evidence that during their rapid formation mother-liquor was enclosed. Owing to this enclosed liquid the double salt dried slowly at $100^{\circ}$, lost further in weight after heating subsequently for many hours at $130^{\circ}$, and further still at $160^{\circ} \mathrm{C}$. The loss at these temperatures compared with the weight after drying three hours at $10^{\circ}$, was equivalent to about six-tenth's per cent. potassium chloride.

When, however, the solution of the potash salt was so dilute that no precipitate was formed on adding the reagent, the potassium platinic salt being deposited on evaporation, the latter was obtained in octahedrons, generally attached to one another forming crystalline plates. These octahedrons were comparatively free from cavities, and practically the same results were secured after drying three hours at $100^{\circ}$, as after drying for many hours at $\mathrm{I} 30^{\circ}$ and $160^{\circ} \mathrm{C}$.

Somewhat lower results were obtained in the presence of sodium chloride and magnesium sulphate, whatever the dilution of the 
solution, but in other respects the above statements will hold true.

The kind of dish used, the temperature of the evaporation, the presence of free hydrochloric acid and free sulphuric acid, dic not appear to influence the results.

A method based on the evaporation of dilute solutions, drying the potassium platinichloride at $100^{\circ}$, and the use of the factors 0.30688 for potassium chloride and 0.1939 for potassium oxide, gave good results and is beliered to be more satisfactory for scientific and practical reasons, than the method of Fresenius, in which the platinum solution is added to concentrated solutions, the double salt is dried many hours at $130^{\circ} \mathrm{C}$. and the factors 0.3056 and 0.19308 are used.

\section{THE INDIRECT ANALYSIS OF MIXTURES CONTAINING A COMMON CONSTITUENT.}

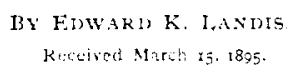

ALCULATION of mixtures containing a common constituent.

Data giaen:

Weight of mixture.

Weight of common constituent in mixture.

Let $x=$ one salt.

Let $y=$ the other.

Let $a=$ amount of common constituent in one part of $x$. Let $b=$ amount of common constituent in one part of $y$. Let $z=$ weight of mixture.

Let $Q=$ weight of common constituent in mixture.

To find ralues of $x$ and $y$;

$x+y=z$.

$a x+b y=Q$.

$a\left(z-y^{\prime}\right)+b y^{\prime}=Q$.

$a z-a y+b y=Q$.

$b^{\prime}-a y^{\prime}=Q-a z$.

$y=\frac{Q-a z}{b-a}$ and $x=z-y$. 